\title{
Paper Titles
}

HomeKey Engineering MaterialsKey Engineering Materials Vol. 907Comparison of the Inhibition Effect of Cedrus...

\section{Comparison of the Inhibition Effect of Cedrus Atlantica and Azadirachta Indica on Low Carbon Steel Corrosion: Data and Statistical Analysis}

38

\begin{abstract}
:
Comparative study of the corrosion inhibition effect of specific concentrations of cedrus atlantica (CA) and azadirachta indica (AI) oil distillates was performed on low carbon steel in $3 \mathrm{M}$ of $\mathrm{C}_{6} \mathrm{H}_{7} \mathrm{O}_{8}$ by coupon analysis. Data obtained showed both distillates performed adequately at all concentrations assessed with principal inhibition value of $94.31 \%$ and $99.59 \%$. The performance of CA oil distillate was concentration dependent compared to Al distillate which showed limited variation with respect to concentration. Statistical computation by analysis of variance shows inspection time and inhibitor concentration influences the inhibition performance of both compounds. The margin of error values shows the performance values of both compounds above $70 \%$ inhibition efficiency is $100 \%(+0 \%)$. Results from standard deviation shows the inhibition efficiency data varied positively with respect inspection time.
\end{abstract}

\section{Access through your institution}

ADD TO CART

Info:

Periodical:

Key Engineering Materials (Volume 907)

Edited by:

Prof. Yuyuan Zhao

Pages:

261-267

DOI:

https://doi.org/10.4028/www.scientific.net/KEM.907.261

Citation:

Cite this paper 
Online since:

January 2022

Authors:

Roland Tolulope Loto*, Cleophas Akinloto Loto, Ayobami Busari Keywords:

Azadirachta Indica, Cedrus Atlantica, Corrosion, Inhibitor, Low Carbon Steel Export:

RIS, BibTeX

Price:

$39,00 €$

Permissions:

Request Permissions

Share:

* - Corresponding Author 